\title{
Extraction of Phenolic Compounds from Palm Oil Processing Residues and Their Application as Antioxidants
}

\section{Erminda Tsouko', Maria Alexandri ${ }^{1}{ }^{2 *}$, Keysson Vieira Fernandes ${ }^{3}$, Denise Maria Guimarães Freire ${ }^{3}$, Athanasios Mallouchos ${ }^{1 *}$ and Apostolis A. Koutinas ${ }^{1}$}

'Department of Food Science and Human Nutrition, Agricultural University of Athens, lera Odos 75, 11855 Athens, Greece

${ }^{2}$ Department of Bioengineering, Leibniz Institute for Agricultural Engineering and Bioeconomy (ATB), Max-Eyth-Allee, 100, 14469 Potsdam, Germany

${ }^{3}$ Biochemistry Department, Chemistry Institute, Federal University of Rio de Janeiro, Cidade Universitária, Centro de Tecnologia, Bloco A, Lab 549, RJ 21941-909, Rio de Janeiro, Brazil

Received: 27 March 2018 Accepted: 12 December 2018

\section{(c) (i) ()}

*Corresponding authors:

Phone: +493315699851

E-mail: malexandri@atb-potsdam.de

Phone: +306944443876

E-mail:aMallouchos@aua.gr

ORCID IDs: 0000-0002-8700-5503 (Tsouko), 0000-0003-2683-8111 (Alexandri), 0000-0003-0521-7631 (Fernandes), 0000-0002-8298-5936 (Freire), 0000-0003-1503-1064 (Mallouchos), 0000-0001-5245-3157 (Koutinas)

\section{SUMMARY}

The side streams derived from the palm oil production process, namely palm kernel cake, palm pressed fibre, palm kernel shells and empty fruit bunches, were evaluated as sources of phenolic compounds. Among these streams, kernel cake had the highest total phenolic content (in mg of gallic acid equivalents (GAE) per $\mathrm{g}$ of dry sample) with a value of 5.19, whereas the empty fruit bunches had the lowest value (1.79). The extraction time and liquid-to-solid ratio were investigated to optimize the phenolic extraction. Kernel cake exhibited the highest total phenolic content $(5.35 \mathrm{mg} / \mathrm{g})$ with a liquid-to-solid ratio of 40:1 during $20 \mathrm{~min}$ of extraction. The main phenolic compounds of the extracts deriving from all byproduct streams were also identified and quantified with HPLC-DAD. Pyrogallol, 4-hydroxybenzoic acid, gallic acid and ferulic acid were the main compounds found in kernel cake extracts. Empty fruit bunch and pressed fibre extracts were also rich in 4-hydroxybenzoic acid, while pyrogallol was the predominant compound in kernel shell extracts. All extracts showed antioxidant activity as it was indicated from the results of DPPH analysis and subsequently tested in sunflower oil aiming to prolong its shelf life. The addition of $0.8 \%$ kernel cake extract increased the induction time of sunflower oil more than $50 \%$. According to the results obtained in this study, kernel cake extracts could be considered as a value-added co-product with a potential application as antioxidants in the food industry.

Key words: palm oil production side streams, phenolics, antioxidant activity, DPPH, induction time, sunflower oil

\section{INTRODUCTION}

Oil palm tree (Elaeis guineensis) is the principal source of palm oil and palm kernel oil. It is estimated that the palm tree yields roughly $10 \%$ of oil, while the remaining $90 \%$ is palm biomass, particularly empty fruit bunches, palm pressed fibre, palm kernel cake, palm kernel shells, oil palm fronds, trunks, leaves and roots and finally palm oil mill effluent. These streams, which amount to 428 million tonnes per year globally (1), are considered as byproducts with restricted applications and a low economic value. So far, they have been disposed in open areas and ponds or have been used as feedstock for incineration, steam and electricity generation, animal feed as well as fungal cultivation (2).

Oil palm mills pose significant environmental concerns through the generation of solid and liquid byproducts during the manufacturing process (Fig. 1) combined with the utilization of excess quantities of water and energy. Consequently, to overcome arising sustainability issues in combination with the financial viability of the process, efficient exploitation of residual palm biomass is required focusing on the production of high value-added products (Fig. 1) such as phytochemicals. Phytochemicals constitute a very promising aspect taking into consideration that the global herbal supplement and remedy market is predicted to reach 8.8 billion US\$ in 2023 at a compound annual growth rate (CAGR) of about $4.7 \%$ (3).

Palm-based phytochemicals mainly include phenolic compounds, terpenes and sterols (4). The largest and more attractive group of the aforementioned phytochemicals encompasses the phenolic compounds, mostly phenolic acids, flavonoids, tannins and lignans. Phenolic compounds, widely distributed as secondary metabolic products, appear 

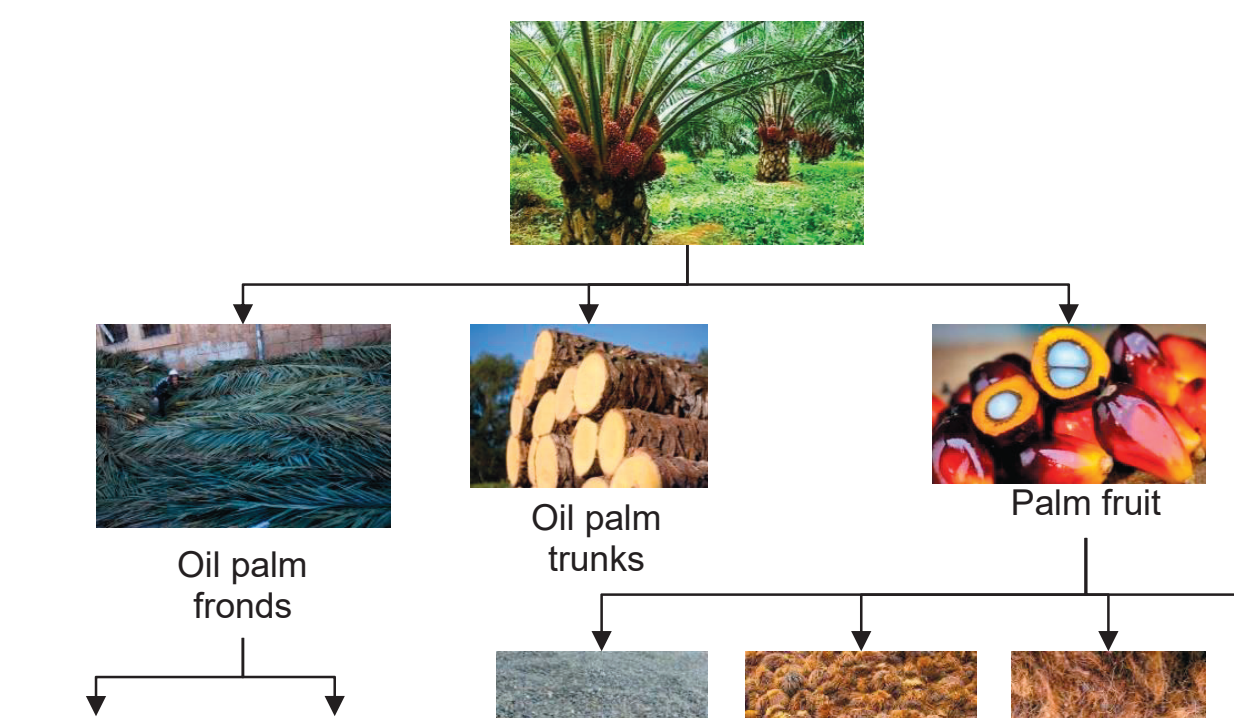

Incineration Combustion for electricity and steam

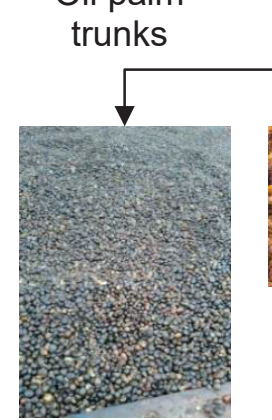

Palm fruit

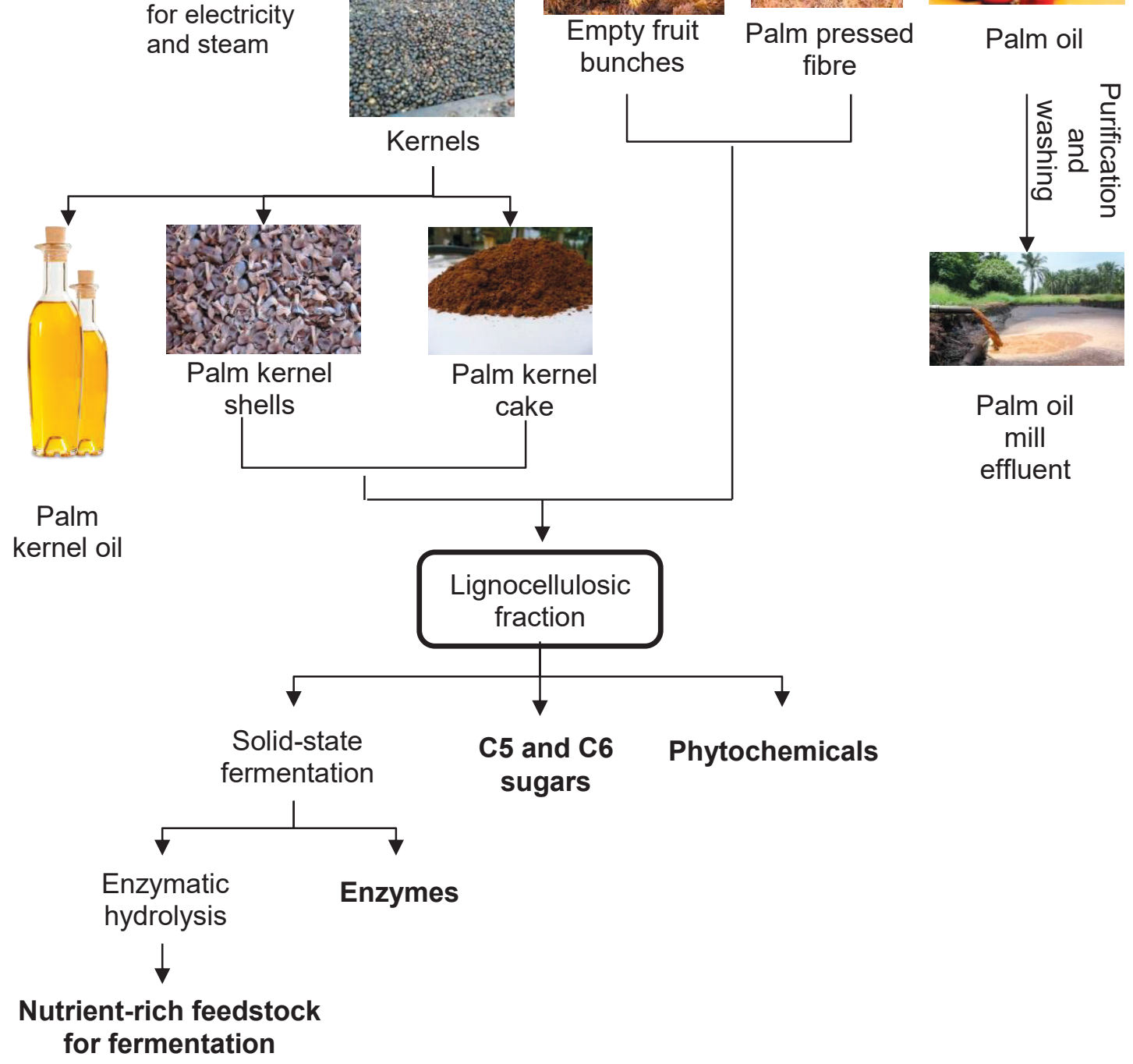

Fig. 1. Flow diagram of palm oil processing residues 
in either free or bound form. They possess remarkable antioxidant activity related to their ability to act as chelators of divalent cations, scavenge free radicals and break radical chain reactions (5).

Several reports have demonstrated possible applications of these bioactive compounds in the pharmaceutical, medical and nutraceutical fields (6-8). Nevertheless, studies on the extraction, recovery and quantification of phenolics from oil palm biomass are rather limited in the literature. Balasundram et al. (9) reported the isolation of a phenol-rich fraction from oil palm fruits. Han and May (10) employed several hydrolytic procedures in order to quantify the extracts of soluble free, insoluble bound and esterified free phenolics in the empty fruit bunches. Nang et al. (11) extracted a phenolic mixture from fresh palm pressed fibre by supercritical carbon dioxide and identified with gas chromatography-mass spectrometry (GC-MS) twelve phenolic compounds that were present in this water-soluble extract. Another study (12) optimized the extraction of phenolic compounds (methanol-soluble and cell wall-bound forms) from the kernel cake. The predominant phenolic compounds in the extracts were $p$-hydroxybenzoic and protocatechuic acids. Neo et al. (13) identified and quantified eight phenolic acids by reversed phase high-performance liquid chromatography (HPLC) with a diode array detector (DAD) and liquid chromatography tandem mass spectrometry, in the phenol-rich extract obtained from the oil palm fruit in soluble free, insoluble bound and esterified forms. Ferulic, $p$-hydroxybenzoic and $p$-coumaric acids were the principal phenolic acids.

Agro-industrial byproducts are good sources of phenolic compounds and they have been explored as a source of natural antioxidants for the maintenance of nutritional quality through the stabilization or shelf life extension of lipids and lipid-containing food products. Rosemary extracts, at a concentration of $500 \mathrm{mg} / \mathrm{L}$, have been reported as very effective natural antioxidants in bulk corn oil and significantly more active than carnosol (14). According to Wanasundara and Shahidi (15), supplementation of canola oil with $0.10 \%$ ethanol extracts from canola meal prolonged the induction time at $65^{\circ} \mathrm{C}$ in comparison with the addition of $0.02 \%$ butylated hydroxyanisole (BHA) and butylated hydroxytoluene (BHT). Goli et al. (16) demonstrated that pistachio hull extracts (at $0.06 \%$ mass fraction) were as effective as $\mathrm{BHA}$ and $\mathrm{BHT}$, when added at $0.02 \%$ mass fraction, in inhibiting oxidation of soybean oil at $60{ }^{\circ} \mathrm{C}$. Phenolic compounds obtained from grape pomace exerted antioxidant effect similar to propyl gallate in fish oil-in-water emulsions (17). The prospect of using phenolic compounds from natural sources as food antioxidants is of paramount industrial interest. However, several issues associated with efficiency of phenolic extraction, availability of feedstock and safety considerations, among others, should be considered to develop food products supplemented with appropriate phenolic formulations (18).

The aim of the current study was initially to screen the phenolic content of various side streams deriving from the palm oil production process and subsequently to choose the stream with the highest phenolic concentration and antioxidant activity. Extraction conditions of kernel cake phenolic compounds were determined by optimizing extraction parameters, namely extraction time and liquid-to-solid ratio. Finally, HPLC-DAD analysis was employed for the identification and quantification of the main phenolic compounds present in the extracts of the solid residues, which were further incorporated into sunflower oil to extend its shelf life.

\section{MATERIALS AND METHODS}

\section{Feedstock}

Palm kernel cake, pressed fibre, kernel shells and empty fruit bunches, which constitute by-product streams generated after the palm oil extraction process, were supplied by the company Companhia Refinadora da Amazônia (Belem, Brazil).

\section{Chemicals}

Methanol (HPLC grade), DPPH, ethanol (analytical grade), butylated hydroxyanisole (BHA) and standard compounds, such as pyrogallol, gallic acid, catechol, homovanillic alcohol, catechin, vanillin, lariciresinol, 4-hydroxybenzoic acid, myricetin, ferulic acid, syringaldehyde, guaiacol and sinapinic acid were purchased from Sigma Aldrich, Merck (Steinheim, Germany). Folin-Ciocalteu phenol reagent (2 M) was purchased from Merck (Darmstadt, Germany).

\section{Extraction of phenolic compounds}

The extraction procedure was carried out in an ultrasonic bath (Elmasonic S10H; Elma, Long Island, NY, USA) using $5 \mathrm{~g}$ sample (on dry basis) and an aqueous solution of ethanol (70\%, by volume) acidified with hydrochloric acid $(0.01 \%$, by volume) as a solvent. Preliminary extraction experiments were conducted to evaluate total phenolic content and antioxidant activity of the side streams. For this purpose, the extraction parameters were fixed as follows: 20 min extraction time and 30:1 liquid-to-solid ratio.

Subsequently, three different extraction times $(10,20$ and $40 \mathrm{~min}$ ) and four different liquid-to-solid ratios (5:1, 20:1, 30:1 and 40:1) were studied to identify the best conditions for the extraction of kernel cake phenolics. After extraction, the samples were filtered and extracts were evaporated at $40^{\circ} \mathrm{C}$ under reduced pressure (rotary evaporator R-114; Büchi Labortechnik, AG, Flawil, Switzerland). The residue was redissolved in $50 \mathrm{~mL}$ acetone/water (1:1, by volume), washed four times with an equal volume of hexane, followed by ethyl acetate extraction (50 mL, four times). The ethyl acetate extracts were combined, and the solvent was evaporated under reduced pressure (19). The residue was redissolved in $10 \mathrm{~mL}$ methanol and kept at $-20^{\circ} \mathrm{C}$ until further analysis. 


\section{Determination of total phenolic content}

The total phenolic content of the methanolic extracts was determined using the Folin-Ciocalteu method, as previously described by Faustino et al. (20) and Papageorgiou et al. (21). Briefly, $50 \mu \mathrm{L}$ extract, $450 \mu \mathrm{L}$ distilled water and $2.5 \mathrm{~mL} 0.2$ $M$ Folin-Ciocalteu reagent were transferred into a test tube, vortexed (VTX-3000L Mixer Uzusio; LMS Co., Tokyo, Japan) for $1 \mathrm{~min}$ and allowed to stand for $8 \mathrm{~min}$. Subsequently, 2 $\mathrm{mL}$ of an aqueous solution of $\mathrm{Na}_{2} \mathrm{CO}_{3}(75 \mathrm{~g} / \mathrm{L})$ were added and the mixture was left to react in the dark for $90 \mathrm{~min}$ at room temperature. The absorbance (relative to that of a blank prepared using methanol instead of extract) was measured at $765 \mathrm{~nm}$ using a double-beam UV-Vis spectrophotometer (model V-530; Jasco, Tokyo, Japan) and compared to the gallic acid calibration curve. The results were expressed in $\mathrm{mg}$ of gallic acid equivalents (GAE) per $g$ of dry byproduct stream.

\section{Determination of the antioxidant activity}

The antioxidant activity of the methanolic extracts was assayed using the DPPH free radical scavenging method as proposed by Scherer and Godoy (22). Briefly, $100 \mu \mathrm{L}$ of diluted $(1: 2,1: 5,1: 10,1: 20 \mathrm{~V} / \mathrm{V})$ methanolic extract were added to $3.9 \mathrm{~mL}$ DPPH solution (80.1 $\mu \mathrm{M}$ in methanol) and left in the dark at room temperature for $90 \mathrm{~min}$. The absorbance was measured at $517 \mathrm{~nm}$ against methanol as a blank, using a double-beam UV-Vis spectrophotometer (model V-530; Jasco). A mixture consisting of $100 \mu \mathrm{L}$ methanol and $3.9 \mathrm{~mL} \mathrm{DPPH}$ solution was used as a control. The antioxidant activity index (AAI) was calculated as suggested and described thoroughly by Scherer and Godoy (22):

$$
\mathrm{AAI}=\frac{\gamma(\mathrm{DPPH})_{\text {final }} /(\mu \mathrm{g} / \mathrm{mL})}{\mathrm{IC}_{50} /(\mu \mathrm{g} / \mathrm{mL})}
$$

where $\mathrm{IC}_{50}$ is the concentration of the methanolic extract providing $50 \%$ inhibition.

\section{Determination of phenolic compounds by HPLC-DAD}

Chromatographic analysis was carried out on a Prominence HPLC system (Shimadzu, Kyoto, Japan), equipped with an on-line degassing unit (DGU-20A), a quaternary pump (LC-20A), an auto sampler (SIL-20A), a column oven (CTO-20A) and a photodiode array detector (SPD-M20A). Separation was performed on a Waters Nova-Pack C18 column (150 mm×3.9 $\mathrm{mm}, 4 \mu \mathrm{m}$ particle size; Milford, CT, USA) at ambient temperature $\left(25^{\circ} \mathrm{C}\right)$ with gradient elution (solution $\mathrm{A}: 0.1 \%$ by volume formic acid in $5 \%$ methanol (Merck) and solution B: $0.1 \%$ by volume formic acid (Merck) in $100 \%$ methanol). The gradient programme was the following: $100 \% \mathrm{~A}$ at $0 \mathrm{~min}, 75 \% \mathrm{~A}$ for $15 \mathrm{~min}, 65 \%$ A for $40 \mathrm{~min}, 55 \%$ A for $60 \mathrm{~min}, 50 \%$ A for $65 \mathrm{~min}$, $0 \%$ A for $90-95 \mathrm{~min}$ and $100 \%$ A for $110-120 \mathrm{~min}$. The flow rate of the mobile phase was $1 \mathrm{~mL} / \mathrm{min}$ and the injection volume was $20 \mu \mathrm{L}$ (23).

Identification of the individual phenolic compounds was based on the comparison of the retention times and the UV spectra of unknown peaks to those of standard compounds. Quantitative analysis was based on calibration curves constructed at specific wavelengths of reference compounds using the external standard method.

\section{Stabilization of sunflower oil using phenolic extracts}

A commercial sunflower oil (Athens, Greece) was supplemented with appropriate amounts of palm kernel cake and palm pressed fibre phenolic extracts. A known volume of methanolic extract isolated as described above was transferred into a test tube and the solvent was evaporated under a nitrogen stream. The residue was redissolved by the addition of $0.8 \mathrm{~mL}$ propylene glycol. Subsequently, $5 \mathrm{~g}$ of sunflower oil were added and the mixture was shaken vigorously (VTX-3000L Mixer Uzusio; LMS Co.) at 150 rpm, for $15 \mathrm{~min}$ at room temperature. Propylene glycol was employed as an aid for the dissolution of phenolics in the oily phase (19). The synthetic antioxidant BHA was also used for comparison at a mass per volume ratio of $0.02 \%(\mathrm{~m} / \mathrm{V})$, which is the maximum allowed.

\section{Accelerated oxidation stability test}

A Metrohm Rancimat model 679 (Herisau, Switzerland) was used to measure the oxidative stability index before and after the enrichment of the sunflower oil with the palm kernel cake and pressed fibre extracts. The tests were carried out with $3 \mathrm{~g}$ oil samples at $120^{\circ} \mathrm{C}$ and at an airflow rate of $20 \mathrm{~L} / \mathrm{h}$. Oxidative stability index was expressed as induction time (h).

\section{Statistical analysis}

JMP v. 8 software (24) was used for statistical analysis. The data were compared using analysis of variance (ANOVA) and Pearson's linear correlation at $5 \%$ significance level. Significant differences between mean values were determined by honestly significant difference (Tukey's HSD test) at $p<0.05$ and $p<0.01$. All values were reported as the mean of three independent determinations and the results were expressed as mean value \pm standard deviation.

\section{RESULTS AND DISCUSSION}

\section{Assessment of total phenolic content and antioxidant activity of oil palm residues}

Preliminary experiments were conducted in the four streams of oil palm solid wastes in order to select the most efficient one in terms of total phenolic content (TPC) and antioxidant activity index (AAI). Table 1 shows the TPC and the AAl of palm kernel cake, pressed fibre, kernel shell and empty fruit bunch extracts from two consecutive extraction cycles. ANOVA results show a statistically significant difference of the mass fractions of total phenolics among the above-mentioned waste streams $(p<0.01)$. The comparison using Tukey's test (Table 1) between total phenolic content of pressed cake 
and kernel shells did not show any statistically significant differences, with respective values (in mg GAE per g dry sample) of 3.59 and 3.66. Empty fruit bunches showed the lowest TPC (1.79 mg/g), while kernel cake exhibited the highest TPC, equal to $5.19 \mathrm{mg} / \mathrm{g}$. Statistically significant differences were demonstrated between the total phenolic content of kernel cake and pressed fibre or empty fruit bunches or kernel shells, of pressed fibre and empty fruit bunches and finally of empty fruit bunches and kernel shells. The kernel cake extract had a relatively higher TPC than the ethanolic extract of sunflower meal, a byproduct from the biodiesel industry that had a TPC value of $4.4 \mathrm{mg} / \mathrm{g} \mathrm{(25)}$ and the sesame cake extract that exhibited a TPC value of $0.81 \mathrm{mg} / \mathrm{g}$ (26).

Table 1. Total phenolic content (in dry matter) and antioxidant activity index of palm kernel cake, palm pressed fibre, palm kernel shell and empty fruit bunch extracts from two extraction cycles at a liquid-to-solid ratio of 30:1 and 20 min extraction time

\begin{tabular}{lcc} 
Oil palm waste stream & $\begin{array}{c}w \text { (total phenolics } \\
\text { as GAE)/(mg/g) }\end{array}$ & $\begin{array}{c}\text { Antioxidant activity } \\
\text { index }\end{array}$ \\
Palm kernel cake & $(5.19 \pm 0.02)^{\mathrm{a}}$ & $1.24 \pm 0.02$ \\
Palm pressed fibre & $(3.59 \pm 0.26)^{\mathrm{b}}$ & $0.91 \pm 0.09$ \\
Palm kernel shells & $(3.66 \pm 0.07)^{\mathrm{b}}$ & $1.48 \pm 0.29$ \\
Empty fruit bunches & $(1.79 \pm 0.05)^{\mathrm{c}}$ & $0.18 \pm 0.03$ \\
\hline
\end{tabular}

Data are presented as mean value \pm standard deviation of three independent replicates $(p<0.01,95 \%)$. Values with different letter in superscript are significantly different $(p<0.05$ and $p<0.01)$. $\mathrm{GAE}=$ gallic acid equivalent

We selected ultrasound-assisted extraction since various studies had proven that it leads to higher extraction efficiency than simple extraction by agitation (27). The negative pressure developed in an ultrasonic bath causes an alteration of the physicochemical properties of the plant matrix, leading to the formation of cavitation bubbles (28). As a result of this phenomenon, the cell membranes get disrupted, increasing the contact between the solvent and the matrix.

The extracts of the four side streams showed antioxidant activity. As estimated by the DPPH assay, the AAI of the extracts followed the order: empty fruit bunch $<$ palm pressed fibre<kernel cake<kernel shells, varying between 0.18 and 1.48. Scherer and Godoy (22) proposed a scale classifying the extracts according to their antioxidant activity as poor if $A A \mathrm{I}<0.5$, as moderate when $0.5<\mathrm{AAl}<1.0$, as strong when $1.0<\mathrm{AAl}<2.0$ and finally as very strong when $\mathrm{AAl}>2$. Consequently, the extracts from empty fruit bunches are categorized as poor antioxidants, those of pressed fibre as moderate ones, whereas the extracts of kernel cake and kernel shells are considered strong antioxidants. A significantly positive correlation was obtained between TPC and AAI at $R^{2}=0.80$ in all four waste streams. Velioglu et al. (29) obtained similar data reporting the TPC and antioxidant activity of 28 plants, including several fruits, vegetables, medicinal plants, as well as sunflower seeds and hull, flaxseeds and wheat germ. They demonstrated a significant relationship between these two factors in all plant materials except for the anthocyanin-rich materials and medicinal plants.
As the palm kernel cake extract had the highest TPC as well as strong antioxidant activity, it was selected for further investigation. Moreover, it is one of the main side streams of the palm fruit processing industry.

\section{Effect of extraction time and liquid-to-solid ratio on TPC and AAl of palm kernel cake}

The extraction time and liquid-to-solid ratio were investigated in order to establish the best values of TPC and AAI of palm kernel cake extracts. Three different extraction times were tested (10, 20 and $40 \mathrm{~min}$ ) and the obtained data are presented in Table 2. ANOVA analysis showed a statistically significant effect of the extraction time on the TPC of kernel cake $(p<0.01)$. It was observed that the lowest TPC $(2.78$ $\mathrm{mg} / \mathrm{g}$ ) was obtained in the shortest extraction time (10 $\mathrm{min})$, and the highest TPC $(6.08 \mathrm{mg} / \mathrm{g})$ in $40 \mathrm{~min}$. There were statistically significant differences in TPC of kernel cake obtained at the three different extraction times at a liquid-to-solid ratio of 30:1. TPC was $15 \%$ higher after 40 min than after 20 min of extraction. Longer extraction times tend to result in an increased extraction efficiency. However, total phenolic potential of the solid matrix must be considered as well as the fact that extended extraction times could also affect the antioxidant activity (Table 2). Finally, Pearson's linear correlation revealed a significantly negative correlation between the TPC and $\mathrm{AAI}\left(\mathrm{R}^{2}=-0.77\right)$. AAI was not significantly affected by any applied regime.

Table 2. Effect of extraction time on total phenolic content (in dry matter) of palm kernel cake and its antioxidant activity index at a liquid-to-solid ratio of 30:1

\begin{tabular}{ccc}
$t($ extraction $) / \mathrm{min}$ & $\begin{array}{c}w \text { (total phenolics as } \\
\mathrm{GAE}) /(\mathrm{mg} / \mathrm{g})\end{array}$ & $\begin{array}{c}\text { Antioxidant activity } \\
\text { index }\end{array}$ \\
10 & $(2.78 \pm 0.14)^{\mathrm{a}}$ & $1.29 \pm 0.06$ \\
20 & $(5.19 \pm 0.02)^{\mathrm{b}}$ & $1.24 \pm 0.02$ \\
40 & $(6.08 \pm 0.16)^{\mathrm{c}}$ & $0.86 \pm 0.16$ \\
\hline
\end{tabular}

Data are presented as mean value \pm standard deviation of three independent replicates $(p<0.01,95 \%)$. Values with different letter in superscript are significantly different $(p<0.05$ and $p<0.01)$. $\mathrm{GAE}=$ gallic acid equivalent

Subsequently, the liquid-to-solid ratios of 5:1, 20:1, 30:1 and 40:1 were investigated and their effect on TPC and AAI is given in Table 3. Increase in the liquid-to-solid ratio improved both TPC and AAI, revealing statistically significant differences as far as TPC was concerned $(p<0.01)$. These results could be attributed to mass transfer phenomena and more specifically to the higher penetration of solvent into plant cells, leading to the release of more phenolic compounds and their easier diffusion into the solvent (30). Tukey's test demonstrated that solely the ratio of 5:1 differs significantly from the other ratios (20:1, 30:1 or 40:1). Finally, a significantly positive correlation between TPC and AAI was demonstrated $\left(R^{2}=0.99\right)$. 
Table 3. Effect of liquid-to-solid ratio on total phenolic content (in dry matter) of palm kernel cake and its antioxidant activity index at 20 min extraction time

\begin{tabular}{ccc} 
Liquid-to-solid ratio & $\begin{array}{c}w \text { (total phenolics as } \\
\mathrm{GAE}) /(\mathrm{mg} / \mathrm{g})\end{array}$ & $\begin{array}{c}\text { Antioxidant activity } \\
\text { index }\end{array}$ \\
$5: 1$ & $(4.33 \pm 0.17)^{\mathrm{a}}$ & $0.69 \pm 0.03$ \\
$20: 1$ & $(4.90 \pm 0.28)^{\mathrm{b}}$ & $1.08 \pm 0.05$ \\
$30: 1$ & $(5.19 \pm 0.02)^{\mathrm{b}}$ & $1.24 \pm 0.02$ \\
$40: 1$ & $(5.35 \pm 0.11)^{\mathrm{b}}$ & $1.34 \pm 0.13$ \\
\hline
\end{tabular}

Data are presented as mean value \pm standard deviation of three independent replicates ( $p<0.01,95 \%)$. Values with different letter in superscript are significantly different $(p<0.05$ and $p<0.01) . G A E=$ gallic acid equivalent

These data are in accordance with other studies, for example Wong et al. (31) studied pH (2-6), temperature (30$\left.80^{\circ} \mathrm{C}\right)$, liquid-to-solid ratio (10:1-100:1), ethanol volume fraction (20-80 \%) and extraction time (30-300 min) during the extraction of phenolic compounds from palm kernel cake. Among these factors, the most important one was the liquid-to-solid ratio, which significantly affected both TPC and antioxidant activity. It was demonstrated that TPC and antioxidant activity increased when the liquid-to-solid ratio was increased from 10:1 to 100:1. However, the effect of extraction time on TPC content was not statistically significant, which is in contrast to our results. Additionally, Bucić-Kojić et al. (32) reported a significant difference in the yield of extracted polyphenols from grape seeds depending on liquid-to-solid ratio, with the highest polyphenol concentration obtained using a ratio of 40:1. Furthermore, Prasad et al. (33) applied a factorial design approach to identify the significant factors contributing to high extraction yield, antioxidant capacity and phenolic content in the extracts from Mangifera pajang pericarp. Ethanol concentration and liquid-to-solid ratio were reported as highly significant contributors.

Another important parameter that affects the extraction is the type of solvent. In the present study, ethanol was selected as the most suitable solvent for phenolic extraction because it is considered a green solvent and the ethanol extracts can be further used in food industry applications. The ethanol volume fraction applied was $70 \%$. According to Markham (34), the extraction efficiency is higher when the solvent consists of a mixture of alcohol and water. Water causes the swelling of biomass and increases the contact surface area, resulting in improved extraction efficiency (35).

\section{Determination of individual phenolic compounds in the extracts of palm oil wastes}

The main phenolic compounds derived from the extraction of the different palm oil wastes were identified by HPLC analysis (Table 4). Eleven compounds were identified in the kernel cake extract with pyrogallol being the predominant one $(1550 \mu \mathrm{g} / \mathrm{g})$, followed by 4-hydroxybenzoic acid (980 $\mu \mathrm{g} / \mathrm{g})$, gallic acid $(590 \mu \mathrm{g} / \mathrm{g})$ and ferulic acid $(560 \mu \mathrm{g} / \mathrm{g})$. Catechol, homovanillyl alcohol and catechin were also detected in significant amounts. In the empty fruit bunches, five compounds were identified with 4-hydroxybenzoic acid being the predominant one $(550 \mu \mathrm{g} / \mathrm{g})$. Four compounds were identified in the palm pressed fibre and five in the kernel shells. The main phenolic compound in the pressed fibre extract was again 4-hydroxybenzoic acid $(760 \mu \mathrm{g} / \mathrm{g})$, whereas pyrogallol was the predominant phenolic compound in the kernel shell extract $(370 \mu \mathrm{g} / \mathrm{g})$. Catechin and 4-hydroxybenzoic acid were present in all residues.

Table 4. Mass fraction of phenolic compounds (in dry matter) found in the extracts of palm kernel cake (PKC), empty fruit bunches (EFB), palm pressed fibre (PPF) and palm kernel shells (PKS)

\begin{tabular}{lccccc}
\multirow{2}{*}{ Compound } & $\lambda / \mathrm{nm}$ & \multicolumn{5}{c}{$w($ phenolics $) /(\mu \mathrm{g} / \mathrm{g})$} \\
\cline { 3 - 6 } Pyrogallol & & PKC & EFB & PPF & PKS \\
Gallic acid & 270 & 1550 & - & - & 370 \\
Catechol & 270 & 590 & 100 & - & - \\
Homovanillic alcohol & 275 & 270 & - & - & - \\
Catechin & 280 & 150 & - & 110 & - \\
Vanillin & 280 & 130 & 50 & 60 & 110 \\
Lariciresinol & 280 & 30 & - & - & 20 \\
4-Hydroxybenzoic acid & 250 & 40 & - & - & - \\
Myricetin & 2880 & 550 & 760 & 230 \\
Ferulic acid & 370 & 50 & - & - & - \\
Syringaldehyde & 325 & 560 & - & - & - \\
Guaiacol & 306 & 30 & 40 & 40 & \\
Sinapinic acid & 270 & - & 150 & - & - \\
Total & 325 & - & - & - & 160 \\
\hline & & 4380 & 890 & 970 & 890 \\
\hline
\end{tabular}

These results are in accordance with the ones obtained in the study of Neo et al. (13), who studied the phenolic content of extracts from oil palm fruits. In their study, the main phenolic compounds identified were 4-hydroxybenzoic, $p$-coumaric and ferulic acids in mass fractions 376,55 and $114 \mu \mathrm{g} / \mathrm{g}$, respectively. Ferulic and 4-hydroxybenzoic acids were also detected in various genera of the Arecaceae family (36). The authors suggested that 4-hydroxybenzoic acid could also be considered as a possible taxonomy marker for palms.

4-Hydroxybenzoic acid has already been applied as a preservative in pharmaceuticals, foods and cosmetics (36). The conventional synthesis of 4-hydroxybenzoic acid involves the chemical reaction of phenol, potassium hydroxide and carbon dioxide under high-pressure conditions. This process bears a high environmental impact not only due to the raw materials but also due to the production of toxic liquid wastes. Finding renewable sources of this phenolic compound is an interesting alternative towards a more sustainable economy. Kawamura et al. (37) proposed that low-molecular-mass phenolic compounds could be used for the production of 2-pyrone-4,6-dicarboxylic acid, which is a precursor for the production of various polymers such as polyamide, polyester and polyurethane.

Pyrogallol and catechol are synthesized in plants through the shikimate pathway. Catechol has been found in extracts from the leaves and needles of various deciduous and coniferous trees, whereas pyrogallol is considered as a product of the 
degradation of plant debris. Moreover, these phenolic compounds are typically found in the soil, and they are also precursors of humic-like polymer synthesis (38). Catechin is a well-known flavonoid and is a plant secondary metabolite. Palm oil is rich in catechin, which has also been found in methanolic leaf extracts of $E$. guineensis together with epicatechin, epigallocatechin, quercetin and rutin among others (39).

Various residues of oilseed crops have been studied for the extraction of phenolic compounds such as sunflower meal and rapeseed meal $(25,40)$. The presence of gallic, vanillic, 4-hydroxybenzoic, ferulic, caffeic and syringic acids is very common in oilseed crops.

Further fractionation of this crude phenolic extract could increase its application and at the same time its market potential. Simple phenolics such as gallic acid, catechol and pyrogallol could be employed to produce fine chemicals, resins, pharmaceuticals and also for food processing and preservation (41). Fini et al. (42) attempted to use pyrolytic lignin instead of fossil bitumen to produce phenolic resins.

Pyrogallol, which is the main phenolic compound identified in the extracts, has a broad range of applications, such as in food, cosmetics, chemical and pharmaceutical industries as well as in photography, printing and production of dyes, due to its antioxidant and antibacterial properties (43). A pyrogallol-based oxygen scavenging system with sodium carbonate was proven to be effective for food packaging applications with low water activity (44). Cotton fabric was also treated with pyrogallol, leading to a final product with $>99.9 \%$ antibacterial ability and $>90 \%$ antioxidant activity (45). Depending on the application purposes and its purity, the price of pyrogallol varies from $\$ 20-100 / \mathrm{kg}$, depending on the supplier.

Ferulic acid, with a broad range of applications, was also present in the extract. This phenolic compound has been reported to increase shelf life of linseed oil and to enhance the stability of lard and soybean oil (46). A mixture of ferulic acid and glycine was proven to completely inhibit the oxidation of biscuits (46). Ferulic acid is also a precursor of vanillin, a well-known flavouring agent widely used in food, beverages and cosmetics (46). Food- or pharmaceutical-grade ferulic acid can cost from US $\$ 100-1000 / k g$, again depending on its purity, origin and the supplier.

\section{Estimation of sunflower oil oxidative stability}

The Rancimat method is widely used to determine the oxidative stability of edible oil. The phenolic extracts from palm kernel cake and pressed fibre were used to enrich sunflower oil in order to increase its stability against oxidation. Palm kernel cake extracts were selected since they exhibited the highest TPC value, and the highest total phenolics as measured by HPLC. Pressed fibre extracts were also tested, mainly for comparison, since it was the stream that, after kernel cake, had the second highest total phenolic mass fraction, determined with HPLC. In both cases, the entire extract was redissolved in propylene glycol and added to $5 \mathrm{~g}$ of sunflower oil. After extraction, the total dry mass of the kernel cake crude extract was $42 \mathrm{mg}$, while the corresponding value of the pressed fibre was $23.2 \mathrm{mg}$. These values correspond to an addition of $0.8 \%$ of kernel cake and $0.46 \%$ of pressed fibre extract.

Butylated hydroxyanisole (BHA) is a synthetic antioxidant commonly used in the food industry because it is cheaper than natural antioxidants and at the same time very efficient (26). For comparison, BHA was also tested at its legal limit $(0.02 \%)$. Sunflower oil without the addition of any antioxidant was also used as control. The results of the Rancimat test are shown in Fig. 2. According to ANOVA, the effect of the extract type on the induction time of the sunflower oil was statistically significant $(p<0.01)$. Tukey's test revealed statistically significant differences among the tested samples (Fig. 2) except for the comparison between $\mathrm{BHA}$ and $0.8 \%$ palm kernel cake extract, which did not show any significant differences. The induction time of the control was only $2.6 \mathrm{~h}$. The addition of $0.46 \%$ palm pressed fibre extract slightly increased the oil induction time (3.4 h). The pressed fibre extract increased induction time up to $30 \%$, and kernel cake extract almost $60 \%$, a result very similar to the one obtained with $\mathrm{BHA}$. The results are very promising, especially considering that $\mathrm{BHA}$ is a pure compound, while the palm kernel cake extract also contains other substances of non-phenolic nature that could even act as pro-oxidants.

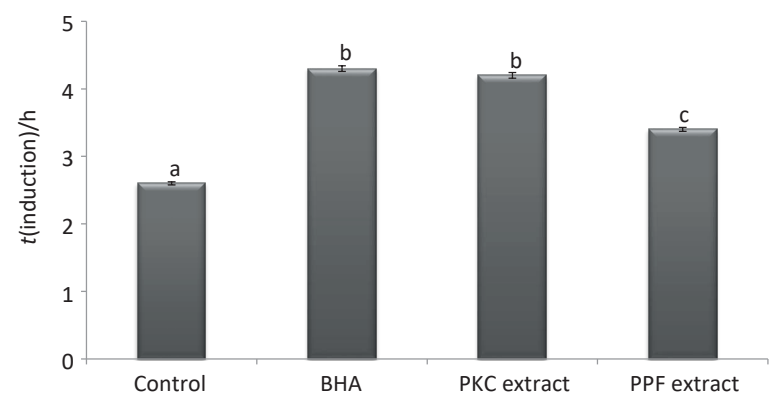

Fig. 2. Oxidation stability index (expressed as induction time) of sunflower oil enriched with $0.8 \%$ palm kernel cake (PKC) extract and 0.46 $\%$ palm pressed fibre (PPF) extract. The induction times of butylated hydroxyanisole (BHA) and the control are given for comparison. Data are presented as mean value \pm standard deviation of three independent replicates $(p<0.01,95 \%)$. Values with different lowercase letter are significantly different $(p<0.05$ and $p<0.01)$

In the literature, there are several studies regarding the addition of extracts from various plant sources to sunflower oil. Gamel and Kiritsakis (47) reported that a $0.02 \%$ rosemary methanolic extract increased the oxidative stability of sunflower oil at 63 and $120^{\circ} \mathrm{C}$. Yanishlieva et al. (48) established that the ethanol extract of summer savory (0.1-0.5\%) improved the oxidative stability of sunflower oil after $50 \mathrm{~h}$ at $180^{\circ} \mathrm{C}$. Finally, the antioxidant activities of six plant extracts (catnip, hyssop, lemon balm, oregano, sage and thyme) added to sunflower oil were evaluated. Sage extracts (600 and $1200 \mathrm{mg} / \mathrm{L}$ ) effectively inhibited the oxidation process in sunflower oil and had higher antioxidant activity than BHT 300 $\mathrm{mg} / \mathrm{L}$ (49). 


\section{CONCLUSIONS}

The byproduct streams of the palm oil production process were used as a source of natural antioxidants. Among the investigated streams, palm kernel cake was the most promising as it had the highest total phenolic content. The highest phenolic extraction from kernel cake was obtained at a liquid-to-solid ratio of 40:1 with 20 min extraction time. The main phenolic compounds were identified with HPLC-DAD and the predominant compounds found in the extract were pyrogallol, 4-hydroxybenzoic, gallic and ferulic acids. The addition of 0.8 $\%$ palm kernel cake extract into sunflower oil resulted in $60 \%$ increase of induction time. These results indicate that the exploitation of the palm oil residues as a source of phenolic compounds could possibly find application in the food industry.

\section{ACKNOWLEDGEMENTS}

The work presented in this study was funded by the National Council for Scientific and Technological Development of the Ministry of Science, Technology and Innovation (CNPq/ MCTI), Brasília, Brazil, through the Special Visiting Researcher fellowship (Process number: 313772/2013-4). Dr Ermida Tsouko would like to thank the Hellenic Foundation for Research and Innovation (H.F.R.I) for scholarly funding her to undertake research at Agricultural University of Athens.

\section{REFERENCES}

1. Market and trade data. Washington, DC, USA: US Department of Agriculture (USDA); 2017. Available from: http:// apps.fas.usda.gov/psdonline/psdquery.aspx.

2. Tsouko E, Kachrimanidou V, dos Santos AF, Lima MEDNV, Papanikolaou S, de Castro AM, et al. Valorization of by-products from palm oil mills for the production of generic fermentation media for microbial oil synthesis. Appl Biochem Biotech. 2017;181(4):1241-56.

https://doi.org/10.1007/s12010-016-2281-7

3. Global herbal supplements and remedies market 2018 by manufacturers, regions, type and application, forecast to 2023. Portland, OR, USA: Global Info Research; 2018. Available from: http://www.arcognizance.com/ report/global-herbal-supplements-and-remedies-market-2018-by-manufacturers-regions-type-and-application-forecast-to-2023.

4. Ofori-Boateng C, Lee KT. Sustainable utilization of oil palm wastes for bioactive phytochemicals for the benefit of the oil palm and nutraceutical industries. Phytochem Rev. 2013; 12(1):173-90.

https://doi.org/10.1007/s11101-013-9270-z

5. Babbar N, Oberoi HS, Uppal DS, Patil RT. Total phenolic content and antioxidant capacity of extracts obtained from six important fruit residues. Food Res Int. 2011;44(1):391-6. https://doi.org/10.1016/j.foodres.2010.10.001

6. Liu Y, Wei S, Liao M. Optimization of ultrasonic extraction of phenolic compounds from Euryale ferox seed shells using response surface methodology. Ind Crop Prod. 2013; 49:837-43.

https://doi.org/10.1016/j.indcrop.2013.07.023

7. Pande H, Kumar B, Varshney VK. Phenolic composition and antioxidant capacity of biomass residue (leaves) generated from Bambusa tulda plantations. Waste Biomass Valor. 2017;8(7):2349-62.

https://doi.org/10.1007/s12649-016-9683-1

8. Xavier L, Freire MS, Vidal-Tato I, González-Álvarez J. Recovery of phenolic compounds from Eucalyptus globulus wood wastes using PEG/phosphate aqueous two-phase systems. Waste Biomass Valor. 2017;8(2):443-52. https://doi.org/10.1007/s12649-016-9579-0

9. Balasundram N, Ai TY, Sambanthamurthi R, Sundram K, Samman S. Antioxidant properties of palm fruit extracts. Asia Pac J Clin Nutr. 2005;14(4):319-24.

10. Han NM, May CY. Determination of antioxidants in oil palm empty fruit bunches. Am J Appl Sci. 2012;9(11):1862-7.

https://doi.org/10.3844/ajassp.2012.1862.1867

11. Nang HLL, May CY, Ngan MA, Hock CC. Extraction and identification of water-soluble compounds in palm pressed fiber by SC- $\mathrm{CO}_{2}$ and GC-MS. Am J Environ Sci. 2007;3(2):54-9. https://doi.org/10.3844/ajessp.2007.54.59

12. Kua SF, Ibrahim J, Ooi CKW, Nan KI, Hashim N, Yusof HM. Optimisation of phenolic extraction and quantification of phenolics in palm kernel cake. Renew Bioresour. 2015;3:2. https://doi.org/10.7243/2052-6237-3-2

13. Neo YP, Ariffin A, Tan CP, Tan YA. Phenolic acid analysis and antioxidant activity assessment of oil palm (E. guineensis) fruit extracts. Food Chem. 2010;122(1):353-9. https://doi.org/10.1016/j.foodchem.2010.02.046

14. Frankel EN, Huang SW, Aeschbach R, Prior E. Antioxidant activity of a rosemary extract and its constituents, carnosic acid, carnosol, and rosmarinic acid, in bulk oil and oil-in-water emulsion. J Agric Food Chem. 1996;44(1):131-5. https://doi.org/10.1021/jf950374p

15. Wanasundara UN, Shahidi F. Canola extract as an alternative natural antioxidant for canola oil. J Am Oil Chem Soc. 1994;71(8):817-22. https://doi.org/10.1007/BF02540455

16. Goli AH, Barzegar M, Sahari MA. Antioxidant activity and total phenolic compounds of pistachio (Pistachia vera) hull extracts. Food Chem. 2005;92(3):521-5.

https://doi.org/10.1016/j.foodchem.2004.08.020

17. Pazos M, Gallardo JM, Torres JL, Medina I. Activity of grape polyphenols as inhibitors of the oxidation of fish lipids and frozen fish muscle. Food Chem. 2005;92(3):547-57. https://doi.org/10.1016/j.foodchem.2004.07.036

18. Balasundram N, Sundram K, Samman S. Phenolic compounds in plants and agri-industrial by-products: Antioxidant activity, occurrence, and potential uses. Food Chem. 2006;99(1):191-203.

https://doi.org/10.1016/j.foodchem.2005.07.042 
19. Salta FN, Mylona A, Chiou A, Boskou G, Andrikopoulos NK. Oxidative stability of edible vegetable oils enriched in polyphenols with olive leaf extract. Food Sci Technol Int. 2007;13(6):413-21.

https://doi.org/10.1177/1082013208089563

20. Faustino H, Gil N, Baptista C, Duarte AP. Antioxidant activity of lignin phenolic compounds extracted from kraft and sulphite black liquors. Molecules. 2010;15(12):9308-22. https://doi.org/10.3390/molecules15129308

21. Papageorgiou V, Gardeli C, Mallouchos A, Papaioannou $M$, Komaitis M. Variation of the chemical profile and antioxidant behavior of Rosmarinus officinalis L. and Salvia fruticosa Miller grown in Greece. J Agric Food Chem. 2008;56(16):7254-64.

https://doi.org/10.1021/jf800802t

22. Scherer R, Godoy HT. Antioxidant activity index (AAI) by the 2,2-diphenyl-1-picrylhydrazyl method. Food Chem. 2009; 112(3):654-8.

https://doi.org/10.1016/j.foodchem.2008.06.026

23. Cai Y, Luo Q, Sun M, Corke H. Antioxidant activity and phenolic compounds of 112 traditional Chinese medicinal plants associated with anticancer. Life Sci. 2004;74(17):2157-84. https://doi.org/10.1016/j.lfs.2003.09.047

24. JMP ${ }^{\oplus}$, v. 8, SAS Institute Inc., Cary, NC, USA; 2009. Available from: https://www.jmp.com/engb/software.htm.

25. Kachrimanidou V, Kopsahelis N, Alexandri M, Strati A, Gardeli C, Papanikolaou S, et al. Integrated sunflower-based biorefinery for the production of antioxidants, protein isolate and poly(3-hydroxybutyrate). Ind Crop Prod. 2015;71:10613.

https://doi.org/10.1016/j.indcrop.2015.03.003

26. Mohdaly AAA, Hassanien MFR, Mahmoud A, Sarhan MA, Smetanska I. Phenolics extracted from potato, sugar beet, and sesame processing by-products. Int J Food Prop. 2013; 16(5):1148-68.

https://doi.org/10.1080/10942912.2011.578318

27. Araújo M, Pimentel FB, Alves RC, Oliveira MBPP. Phenolic compounds from olive mill wastes: Health effects, analytical approach and application as food antioxidants. Trends Food Sci Tech. 2015;45(2):200-11. https://doi.org/10.1016/j.tifs.2015.06.010

28. Chen D, Sharma SK, Mudhoo A, editors. Handbook on applications of ultrasound: Sonochemistry for sustainability. Boca Raton, FL, USA: CRC Press; 2012.

29. Velioglu YS, Mazza G, Gao L, Oomah BD. Antioxidant activity and total phenolics in selected fruits, vegetables and grain products. J Agric Food Chem. 1998;46(10):4113-7. https://doi.org/10.1021/jf9801973

30. Radojković M, Zeković Z, Jokić S, Vidović S, Lepojević Ž, Milošević S. Optimization of solid-liquid extraction of antioxidants from black mulberry leaves by response surface methodology. Food Technol Biotechnol. 2012;50(2):167-76.
31. Wong WH, Lee WX, Ramanan RN, Tee LH, Kong KW, Galanakis $C M$, et al. Two level half factorial design for the extraction of phenolics, flavonoids and antioxidants recovery from palm kernel by-product. Ind Crop Prod. 2015;63:238-48.

https://doi.org/10.1016/j.indcrop.2014.09.049

32. Bucić-Kojić A, Planinić $M$, Tomas S, Bilić M, Velić D. Study of solid-liquid extraction kinetics of total polyphenols from grape seeds. J Food Eng. 2007;81(1):236-42.

https://doi.org/10.1016/j.jfoodeng.2006.10.027

33. Prasad KN, Kong KW, Ramanan RN, Azlan A, Ismail A. Selection of experimental domain using two-level factorial design to determine extract yield, antioxidant capacity, phenolics, and flavonoids from Mangifera pajang Kosterm. Sep Sci Technol. 2012;47(16):2417-23.

https://doi.org/10.1080/01496395.2012.672511

34. Markham KR, editor. Techniques of flavonoid identification, vol. 31. London, UK: London Academic Press;1982.

35. Xiao W, Han L, Shi B. Optimization of microwave-assisted extraction of flavonoid from Radix astragali using response surface methodology. Sep Sci Technol. 2008;43(3):671-81. https://doi.org/10.1080/01496390701812509

36. Chakraborty M, Das K, Dey G, Mitra A. Unusually high quantity of 4-hydroxybenzoic acid accumulation in cell wall of palm mesocarps. Biochem Syst Ecol. 2006;34(6):509-13. https://doi.org/10.1016/j.bse.2005.11.011

37. Kawamura F, Saary NS, Hashim R, Sulaiman O, Hashida K, Otsuka $Y$, et al. Subcritical water extraction of low-molecular-weight phenolic compounds from oil palm biomass. JARQ-Jpn Agr Res Q. 2014;48(3):355-62.

https://doi.org/10.6090/jarq.48.355

38. Kocaçalışkan I, Talan I, Terzi I. Antimicrobial activity of catechol and pyrogallol as allelochemicals. Z Naturforsch C. 2006;61(9-10):639-42.

https://doi.org/10.1515/znc-2006-9-1004

39. Jaffri JM, Mohamed S, Rohimi N, Ahmad IN, Noordin MM, Manap YA. Antihypertensive and cardiovascular effects of catechin-rich oil palm (Elaeis guineensis) leaf extract in nitric oxide-deficient rats. J Med Food. 2011;14(7-8):775-83. https://doi.org/10.1089/jmf.2010.1170

40. Vuorela S, Meyer AS, Heinonen M. Impact of isolation method on the antioxidant activity of rapeseed meal phenolics. J Agric Food Chem. 2004;52(26):8202-7.

https://doi.org/10.1021/jf0487046

41. Kim JS. Production, separation and applications of phenolic-rich bio-oil - A review. Bioresour Technol. 2015;178:90-8. https://doi.org/10.1016/j.biortech.2014.08.121

42. Fini EH, Kalberer EW, Shahbazi A, Basti M, You Z, Ozer H, Aurangzeb Q. Chemical characterization of biobinder from swine manure: Sustainable modifier for asphalt binder. J Mater Civil Eng. 2011;23(11):1506-13. https://doi.org/10.1061/(ASCE)MT.1943-5533.0000237 
43. Wang J, Shen X, Yuan Q, Yan Y. Microbial synthesis of pyrogallol using genetically engineered Escherichia coli. Metab Eng. 2018;45:134-41.

https://doi.org/10.1016/j.ymben.2017.12.006

44. Gaikwad KK, Lee YS. Novel natural phenolic compound-based oxygen scavenging system for active packaging applications. J Food Meas Charact. 2016;10(3):533-8. https://doi.org/10.1007/s11694-016-9332-1

45. Hong KH. Preparation and properties of phenolic compound/BTCA treated cotton fabrics for functional textile applications. Cellulose. 2015;22(3):2129-36. https://doi.org/10.1007/s10570-015-0604-4

46. Kumar N, Pruthi V. Potential applications of ferulic acid from natural sources. Biotechnol Rep. 2014;4:86-93.

https://doi.org/10.1016/j.btre.2014.09.002
47. Gamel TH, Kiritsakis A. Effect of methanol extracts of rosemary and olive vegetable water on the stability of olive oil and sunflower oil. Grasas Aceites. 1999;50(5):345-50.

https://doi.org/10.3989/gya.1999.v50.i5.677

48. Yanishlieva NV, Marinova EM, Marekov IN, Gordon MH. Effect of an ethanol extract from summer savory (Saturejae hortensis L.) on the stability of sunflower oil at frying temperature. J Sci Food Agr. 1997;74(4):524-30.

https://doi.org/10.1002/(SICI)1097-

0010(199708)74:4<524::AID-JSFA829>3.0.CO;2-W

49. Abdalla $A E$, Roozen JP. Effect of plant extracts on the oxidative stability of sunflower oil and emulsion. Food Chem. 1999;64(3):323-9.

https://doi.org/10.1016/S0308-8146(98)00112-5 